\title{
Разработка полиакриламидных композиций, наполненных клиноптилолитовыми породами для адсорбционной очистки воды от нефтепродуктов
}

\author{
Дабижа O.H. \\ Забайкальский государственный университет, Чита \\ Забайкальский институт железнодорожного транспорта, Чита
}

Поступила в редакцию 20.07.2018 г.

DOI: https://doi.org/10.17308/sorpchrom.2019.19/646

\begin{abstract}
Синтезированы композиционные материалы с улучшенными нефтесорбционными свойствами на основе наполненного клиноптилолитовыми породами полиакриламида. Полученные композиты изучены методами оптической микроскопии, инфракрасной спектроскопии, дифференциальной сканирующей калориметрии и термогравиметрии. Рассмотрены вероятные варианты взаимодействий между активными центрами наполненной полимерной системы с участием молекул воды. Определены оптимальные содержания дисперсного наполнителя и концентрация водного раствора полиакриламида для получения материала с максимальной экспертной оценкой и степенью очистки морской воды от нефти и дизельного топлива.
\end{abstract}

Ключевые слова: клиноптилолит, полиакриламид, активные центры, сорбенты, нефть, дизельное топливо, органоминеральный комплекс.

\section{Development of polyacrylamide compositions, filled with clinoptilolite rocks for adsorption treatment of water from petroleum products}

\author{
Dabizha O.N. \\ Transbaikal State University, Chita \\ Transbaikal Institute of Railway Transport, Chita
}

The article is devoted to the problem of development of inexpensive and ecologically safe organomineral petroleum sorbents on the basis of industrial water-soluble polymer filled with clinoptilolite rocks of the largest in Russia Kholinsk and Shivirtuy deposits. The prospect of using zeolites as fillers is explained by their nanoporous structure, mechanical and thermal stability, availability, and also by excellent sorption properties. The choice of polyacrylamide is due to its coagulation properties and wide application for wastewater treatment. The purpose of this work is the synthesis and study of composite materials based on polyacrylamide and clinoptilolite rocks with improved sorption properties in relation to petroleum products.

Aqueous solutions of polyacrylamide were filled with highly disperse mechanoactivated clinoptilolite rocks by stirring for 10 minutes on a magnetic stirrer. Films were obtained by watering on glass and polypropylene substrates and further removal of the solvent at $25^{\circ} \mathrm{C}$. Probable types of interaction of active sites, taking into account the quasi-chemical model of water vapor sorption, have been proposed. Complexation through intermolecular hydrogen bonds involving the functional groups of the polymer, silanol groups of clinoptilolite and water molecules was confirmed by infrared spectroscopy, differential scanning calorimetry and thermogravimetry. The heterogeneous structure of the samples was studied by optical microscopy. It has been established that clinoptilolite rocks exhibit structural activity with respect to the polyacrylamide matrix. The presence of a network structure and a complex relief in the investigated samples of polymer composites 
is shown. The Coates-Redfern method was used to calculate the order of thermolysis of polyacrylamide films obtained from the initial and filled 0.2 wt. \% clinoptilolite rocks of aqueous solutions of $4 \mathrm{~g} / 100 \mathrm{~cm}^{3}$ and effective activation energies in the temperature range from 100 to $500{ }^{\circ} \mathrm{C}$. It was found that the maximum expert estimates and the prospect of use in cleaning model sea water from oil and diesel fuel showed a sample obtained on the basis of $4 \mathrm{~g} / 100 \mathrm{~cm}^{3}$ of polyacrylamide and $0.2 \%$ of the clinoptilolite rocks of the Shivirtuy deposit.

Keywords: clinoptilolite, polyacrylamide, active centers, sorbents, petroleum, diesel fuel, organomineral complex.

\section{Введение}

Композиционные материалы на основе неорганических коагулянтов и органических водорастворимых полимеров, в том числе полиакриламида (ПАА), все чаще используются для очистки сточных вод [1-3]. Цеолиты являются перспективными нанопористыми наполнителями для полимеров, обладают нефтесорбционными свойствами [4-6], характеризуются невысокой себестоимостью, радиационной и термической устойчивостью, экологической безопасностью. Синергизм коагуляционных и сорбционных свойств при совместном использовании ПАА и цеолитов может способствовать улучшению технологических свойств композиционного материала, полученного на их основе. В этой связи разработка перспективных экологически безвредных и недорогих органоминеральных нефтесорбентов с высокими эксплуатационными характеристиками с применением полиакриламида и местного цеолитсодержащего сырья представляет актуальную задачу.

Цель настоящей работы: синтез и исследование композиционных материалов на основе ПАА и клиноптилолитовых пород с улучшенными сорбционными свойствами по отношению к нефтепродуктам.

\section{Эксперимент}

В качестве матрицы использовали ПАА марки 130617, Китай (pH=7-13; $\rho=1.302$ г $/ \mathrm{cm}^{3} ; \mathrm{t}_{\text {стекл }}=190^{\circ} \mathrm{C} ; \eta$ раствора 0.25 мас. \% ПАА в растворе $3 \% \mathrm{NaCl}$ при $30^{\circ} \mathrm{C}$ не менее $2.2 \mathrm{Mm}^{2} / \mathrm{c}$ ).

Минеральными наполнителями выбраны клиноптилолитовые породы крупнейших в России Холинского (ХЦ) и Шивыртуйского (ШЦ) месторождений (Забайкальский край). Фазовый состав: клиноптилолит; стильбит; полевой шпат; кварц (ХЦ); клиноптилолит; полевой шпат; кварц (ШЦ). Химический состав w, \%: $\mathrm{SiO}_{2}$ 74.94; $\mathrm{Al}_{2} \mathrm{O}_{3}$ 11.92; $\mathrm{TiO}_{2}$ 0.12; $\mathrm{Fe}_{2} \mathrm{O}_{3}$ 0.67; $\mathrm{CaO} 1.54 ; \mathrm{MgO} 0.18 ; \mathrm{Na}_{2} \mathrm{O} 1.72 ; \mathrm{K}_{2} \mathrm{O} 4.24$ (ХЦ); $\mathrm{SiO}_{2}$ 69.42; $\mathrm{Al}_{2} \mathrm{O}_{3}$ 13.06; $\mathrm{TiO}_{2}$ 0.34; $\mathrm{Fe}_{2} \mathrm{O}_{3}$ 2.14; $\mathrm{CaO}$ 3.00; $\mathrm{MgO} 0.84 ; \mathrm{Na}_{2} \mathrm{O} 1.30 ;$ $\mathrm{K}_{2} \mathrm{O} 2.95$ (ШЦ) [7]. Воздушно-сухие клиноптилолитовые породы измельчали 2 минуты в дробилке BOYD MK III, далее подвергали механоактивации в течение 3 минут в дисковой вибрационной мельнице Essa LM2-P. Из полученного порошка высеивали высокодисперсную фракцию ( $\mathrm{r} \leq 0.30$ мм).

Полимерные композиционные материалы получали тщательным перемешиванием в течение 10 минут на магнитной мешалке водных растворов ПАА с высокодисперсной фракцией клиноптилолитовой породы. Концентрацию полимера и содержание минерального наполнителя варьировали в следующих пределах: $1 ; 2 ; 4$ г/100 $\mathrm{cm}^{3}$ и $0.1 ; 0.2 ; 0.3 ; 0.4$ мас. \% соответственно. Пленки полимерных композитов получали поливом на наклонные стеклянные и полипропиленовые пластины и испарением растворителя при $25^{\circ} \mathrm{C}$. 
ИК-спектры поглощения полимерных пленок регистрировали спектрометром SHIMADZU FTIR-8400S в области 4000-400 $\mathrm{cm}^{-1}$. Для расшифровки ИК-спектров использовали специальную литературу [8].

Кривые дифференциальной сканирующей калориметрии (ДСК), термогравиметрии (ТГ) и дифференциальной термогравиметрии (ДТГ) регистрировали синхронным термоанализатором STA 449F1 (фирма NETZSCH, Германия). Образцы массой $41 \ldots 42$ мг нагревали от 25 до $600^{\circ} \mathrm{C}$ в платиновых тиглях в динамической атмосфере аргона со скоростью $10^{\circ} \mathrm{C} /$ мин.

Эффективную энергию активации Е рассчитывали методом Коутса-Редферна:

$$
\begin{array}{cc}
\ln \left[-\frac{\ln (1-\alpha)}{T^{2}}\right]=-\left(\frac{E}{R T}\right)+\ln \left(\frac{A R}{\beta E}\right)\left(1-\frac{2 R T}{E}\right) & \text { (для } \mathrm{n}=1) \\
\ln \left[\frac{1-(1-\alpha)^{1-n}}{(1-n) T^{2}}\right]=-\left(\frac{E}{R T}\right)+\ln \left(\frac{A R}{\beta E}\right)\left(1-\frac{2 R T}{E}\right) & \text { (для } n \neq 1) \\
\alpha=\mathrm{m}_{\mathrm{t}} / \mathrm{m}_{0} &
\end{array}
$$

где $\alpha$ - массовая доля образца, разложившаяся за время $\mathrm{t}$; $\mathrm{m}_{0-}$ максимальная потеря массы образца; $\mathrm{m}_{\mathrm{t}}$ - потеря массы образца за время $\mathrm{t} ; \mathrm{n}$ - порядок реакции; $\mathrm{T}$ - температура, K; R = 8.314 Дж/моль·К; А - предэкспоненциальный множитель; $\beta$ - скорость нагрева, К/мин.

Значения порядка реакции в уравнении (2) подбирали, варьируя $n=0 \ldots 2$ с шагом 0.1. Погрешность определения эффективной энергии активации составляла \pm 2.0 кДж/моль.

Морфологию композитов изучали исследовательским стереомикроскопом с функцией плавного увеличения (ZOOM) серии RZ производства MEIJI TECHNO CO., LTP, Япония. Качество пленок оценивали ранговым методом [9] по пятибалльной порядковой шкале.

Для моделирования разливов нефти на поверхности природного водоема химический стакан заполняли 0.25 дм $^{3}$ приготовленной морской водой $(27.5 \mathrm{NaCl} ; 5.0$ $\mathrm{MgCl} ; 2.0 \mathrm{MgSO}_{4} \cdot 7 \mathrm{H}_{2} \mathrm{O} ; 0.5 \mathrm{CaCl}_{2} ; 1.0 \mathrm{KCl} ; 0.001 \mathrm{Fe}_{2}\left(\mathrm{SO}_{4}\right)_{3}$, г/л), добавляли 1.5 г нефтепродукта, выдерживали до образования на поверхности однородной пленки нефти («Реахим» ГОСТ 9965-76) или дизельного топлива (Роснефть, ГОСТ Р 52368). Имитацию волн осуществляли с помощью шейкера (скорость 100 об/мин; 5 минут). На поверхность полученной морской воды наносили 0.2 г испытуемых образцов: 4; 4 0,2ШЦ(ХЦ) и 4-0,4ХЦ(ШЦ) - водные растворы ПАА 4 г/100 $\mathrm{cm}^{3}$, исходный и модифицированные 0.2 и 0.4 мас. \% дисперсными минеральными наполнителями.

Степень очистки поверхности воды от нефти контролировали по величине отношения площади поверхности жидкости, освободившейся от нефти, ко всей поверхности и оценивали по пятибалльной шкале методом экспертных оценок [10]. Поверхность дна, полностью загрязненная нефтью соответствует 0 баллов очистки, а незагрязненной поверхности соответствует высший балл.

\section{Обсуждение результатов}

Как известно [11], структура в наполненном полимерном растворе может формироваться по адсорбционному механизму между частицами наполнителя через прослойки полимера. В сорбции могут принимать участие также молекулы воды. Учитывая квазихимическую модель сорбции паров воды [12], предполагаются следующие варианты взаимодействия функциональных групп $\mathrm{A}_{1}$ и $\mathrm{A}_{2}$ (рис. 1) с образованием различных комплексов, в том числе органоминеральных. 


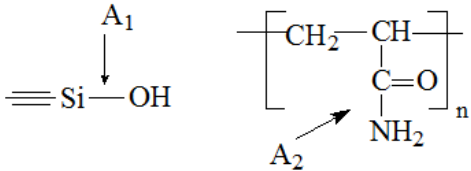

$$
\begin{aligned}
& \mathrm{A}_{1}+\mathrm{A}_{2} \rightleftharpoons \mathrm{A}_{1}{ }^{*} \mathrm{~A}_{2}(\mathrm{I}) \\
& \mathrm{nH}_{2} \mathrm{O}+\mathrm{A}_{1} \rightleftharpoons \mathrm{A}_{1}{ }^{*}\left(\mathrm{H}_{2} \mathrm{O}\right)_{\mathrm{n}} \text { (II) } \\
& \mathrm{mH}_{2} \mathrm{O}+\mathrm{A}_{2} \rightleftharpoons \mathrm{A}_{2}{ }^{*}\left(\mathrm{H}_{2} \mathrm{O}\right)_{\mathrm{m}} \text { (III) } \\
& \mathrm{xH}_{2} \mathrm{O}+\mathrm{A}_{1}{ }^{\star} \mathrm{A}_{2} \rightleftharpoons\left(\mathrm{A}_{1}{ }^{*} \mathrm{~A}_{2}\right)^{*}\left(\mathrm{H}_{2} \mathrm{O}\right)_{\mathrm{x}} \text { (IV) } \\
& \mathrm{A}_{1}{ }^{*}\left(\mathrm{H}_{2} \mathrm{O}\right)_{\mathrm{n}}+\mathrm{A}_{2}{ }^{*}\left(\mathrm{H}_{2} \mathrm{O}\right)_{\mathrm{m}} \rightleftharpoons \mathrm{A}_{1}{ }^{*}\left(\mathrm{H}_{2} \mathrm{O}\right)_{\mathrm{n}}{ }^{*} \mathrm{~A}_{2}{ }^{*}\left(\mathrm{H}_{2} \mathrm{O}\right)_{\mathrm{m}}(\mathbf{V})
\end{aligned}
$$

$\mathrm{A}_{1}$ и $\mathrm{A}_{2}$ - силанольная и карбамидная функциональные группы; I, II, III, IV - комплексы

Рис. 1. Активные центры (функциональные группы)

и варианты их взаимодействия между собой и с молекулами воды

Комплексообразование подтверждается сдвигом в низкочастотную область п.п. асимметричных и симметричных валентных колебаний групп $\mathrm{NH}_{2}$. Широкая п.п. в области $3300 \mathrm{~cm}^{-1}$ отвечает валентным колебаниям N-H и перекрыта валентными колебаниями О-Н. В ИК-спектре 1-0,1ШЦ п.п., характерные для первичного амида, наблюдаются при 3339 и $3196 \mathrm{~cm}^{-1}$, в то время как у образца $1-$ при 3350 и $3200 \mathrm{~cm}^{-1}$. В ИК-спектрах образцов 1-0,1ХЦ и 1-0,3ХЦ появляются слабые п.п. с максимумами при 2793-2795 см-1, а в 1-0,4ХЦ - при 3729 и $3624 \mathrm{~cm}^{-1}$. Аналогично в ИК-спектре 10,3ШЦ появляется слабая п.П. при $2797 \mathrm{~cm}^{-1}$, а в 2-0,2ШЦ - $3732 \mathrm{~cm}^{-1}$. П.п. в области 3700-3600 $\mathrm{cm}^{-1}$ обусловлены валентными колебаниями свободных гидроксильных групп на поверхности клиноптилолита (三Si-OH).

Увеличение концентрации ПАА в полимерных композитах приводит к увеличению смещения п.п. Так, для образцов 2-0,2ХЦ, 2-0,2ШЦ п.п. $v_{\mathrm{as}} \mathrm{NH}_{2}$ в ИК-спектрах наблюдаются при 3350 и $3339 \mathrm{~cm}^{-1}$ соответственно, а п.п. $\mathrm{C}_{\alpha} \mathrm{N}$ в 2-0,2 ХЦ - при 1184 $\mathrm{cm}^{-1}$, а у исходного образца 2 эти полосы регистрируются при 3356 и $1174 \mathrm{~cm}^{-1}$. П.П. $v_{\text {as }} \mathrm{NH}_{2}$ в ИК-спектрах композитов 4-0,2ХЦ и 4-0,2ШЦ смещаются в сравнении с образцом 4 в сторону более низких частот на $9 ; 8 \mathrm{~cm}^{-1}$ соответственно, в ИК-спектре образца 4-0,2ХЦ наблюдается высокочастотное смещение п.п. $v \mathrm{C}_{\alpha} \mathrm{N}$ на $15 \mathrm{~cm}^{-1}$. Очень слабые п.п. с максимумами при 995 и $926 \mathrm{~cm}^{-1}$, наблюдаемые в ИК-спектре композита 4-0,2ШЦ относятся к валентным колебаниям групп Si-O-Al минерального наполнителя [13].

Наблюдаемые изменения в ИК-спектрах образцов показали, что в полимерных наполненных композитах происходит усиление структурообразования благодаря межмолекулярным водородным связям между ( $=\mathrm{Si}-\mathrm{OH})$ группами клиноптилолитов и $\left(-\mathrm{C}(=\mathrm{O}) \mathrm{NH}_{2}\right)$ группами гидрофильного ПАА с участием молекул $\mathrm{H}_{2} \mathrm{O}$, которые образуют дополнительную сетку, компенсирующую рост неоднородности и дефектности в граничных слоях, как и в работе [14].

Присутствие минерального наполнителя обуславливает возникновение гетерогенной структуры, что показано методом оптической микроскопии (рис. 2). Выявлено, что для образцов 1-0,2ХЦ и 1-0,2ШЦ характерно образование агрегатов из частиц клиноптилолитовой породы и неравномерное распределение их по объему ПАА матрицы. Максимально выраженный рельеф и образование сетчатой структуры со вторичными агрегатами - упрочненными адсорбированными частицами клиноптилолитовой породы макромолекулами ПАА - наблюдается в композитах 4-0,2ХЦ и 40,2ШЦ. Следовательно, концентрация полимера 4 г/100 $\mathrm{cm}^{3}$ определяет возможность формирования трехмерной структурной сетки наполненных полиакриламидных композитов. Именно в этих образцах, с максимальной степенью выраженности 
структурных изменений, можно ожидать улучшения сорбционных свойств. Как известно, увеличение концентрации полимерной матрицы приводит к повышению вклада надмолекулярных образований в структуру композиции [15]. Следовательно, можно ожидать усиления адсорбционного взаимодействия ПАА-наполнитель и упрочнения структуры полимерных композитов [16].

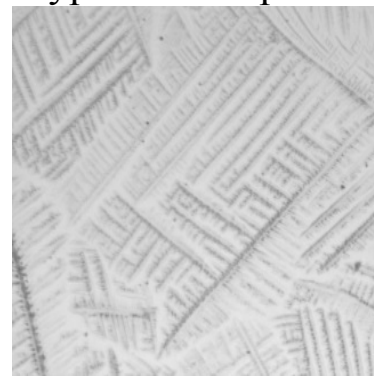

1

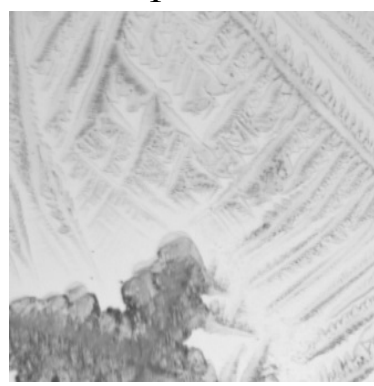

2

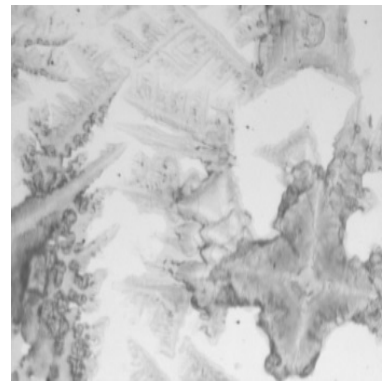

4

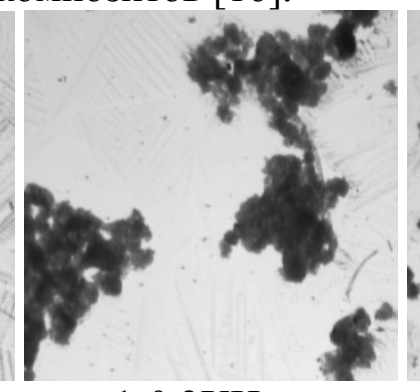

$1-0,2$ ХЦ

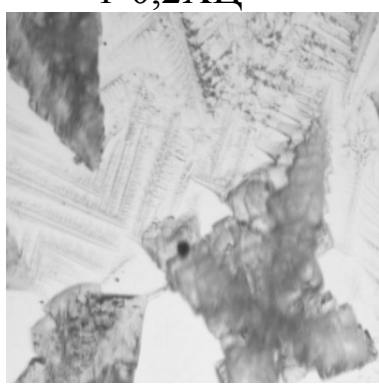

2-0,2ХЦ

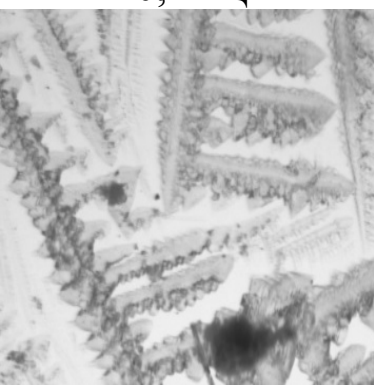

4-0,2ХЦ

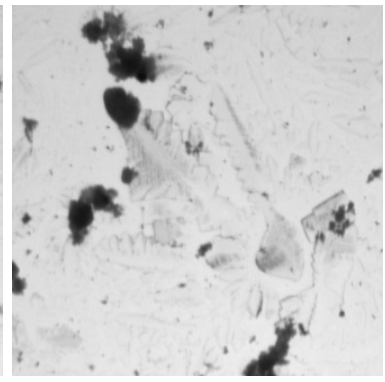

1-0,2ШЦ

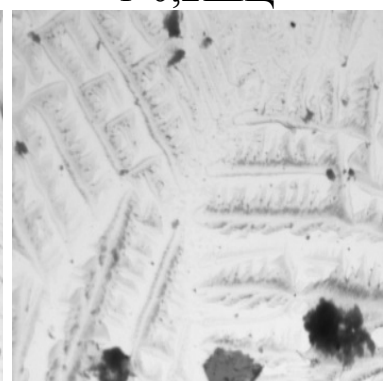

2-0,2ШЦ

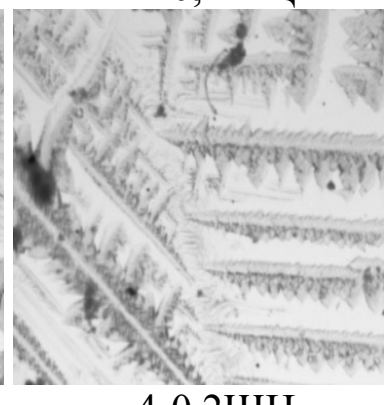

4-0,2ШЦ

Рис. 2. Фотографии пленок исследуемых образцов (увеличение 750 крат.)

Анализ термограмм пленок 4; 4-0,2ХЦ и 4-0,2ШЦ показал (табл. 1), что наполнение ПАА клиноптилолитовой породой способствует сдвигу двух эндотермических эффектов, связанных с испарением воды, на термограммах на 3-4 ${ }^{\circ} \mathrm{C}$ в сторону более высоких температур, следовательно, повышается термоустойчивость материала. Термолиз образцов происходит в три этапа, на что указывают перегибы на ТГкривых и количество экстремумов ДТГ-кривых. Экзотермический эффект на термограмме 4-0,2ХЦ, изменение порядка процесса термолиза и эффективной энергии активации свидетельствуют о формировании органоминерального комплекса и согласуются с результатами инфракрасной спектроскопии и оптической микроскопии.

Таблица 1. Температуры эндотермических и экзотермических эффектов, потери массы при $600^{\circ} \mathrm{C}$, порядок реакции, эффективная энергия активации, достоверность аппроксимации при линеаризации кривых термогравиметрии

\begin{tabular}{|c|c|c|c|c|c|c|c|}
\hline Образцы & \multicolumn{2}{|c|}{$\mathrm{t}_{\text {эндо- }}{ }^{\circ} \mathrm{C}$} & $\mathrm{t}_{\text {экзо- }}{ }^{\circ} \mathrm{C}$ & $\Delta \mathrm{m}_{600}, \%$ & $\mathrm{n}$ & $\mathrm{E}$, кДж/моль & $\mathrm{R}^{2}$ \\
\hline 4 & 117 & 252 & - & 5.23 & 1.0 & 14.55 & 0.9996 \\
\hline $4-0,2$ ХЦ & 120 & 256 & 319 & 5.87 & 1.4 & 16.43 & 0.9874 \\
\hline $4-0,2 Ш Ц$ & 121 & 260 & - & 5.08 & 1.8 & 19.80 & 0.9867 \\
\hline
\end{tabular}


Экспериментально установлено, что максимальные степень очистки воды от нефтепродуктов и экспертную оценку получил полимерный композит 4-0,2ШЦ (табл. 2). Наполнитель - клиноптилолитовая порода Шивыртуйского месторождения - обеспечивает надежную плавучесть загущаемой полиакриламидом нефти.

Таблица 2. Оценка очистки поверхности морской воды от нефтепродуктов (НП) с применением исследуемых образцов

\begin{tabular}{|c|c|c|c|c|c|}
\hline \multirow{2}{*}{ Образцы } & \multicolumn{2}{|c|}{$\begin{array}{l}\text { Степень очистки } \\
\text { поверхности воды }\end{array}$} & \multicolumn{2}{|c|}{ Экспертная оценка } & \multirow{2}{*}{$\begin{array}{c}\text { Примечания } \\
\text { Нефть / Диз. топливо }\end{array}$} \\
\hline & Нефть & $\begin{array}{l}\text { Диз. топ- } \\
\text { ливо }\end{array}$ & Нефть & $\begin{array}{l}\text { Диз. топ- } \\
\text { ливо }\end{array}$ & \\
\hline 4 & 0.008 & 0.008 & 1 & 1 & $\begin{array}{c}\text { Образец концентрирован в одной } \\
\text { области, на дно не падает }\end{array}$ \\
\hline 4-0,2ХЦ & 0.081 & 0.077 & 3 & 3 & $\begin{array}{c}\text { Малая часть образца опустилась на } \\
\text { дно, захватив частицы НП }\end{array}$ \\
\hline 4-0,2ЩЦ & 0.140 & 0.088 & 4 & 3 & $\begin{array}{c}\text { Образец устойчив на поверхности } \\
\text { воды }\end{array}$ \\
\hline 4-0,4ХЦ & 0.020 & 0.018 & 2 & 2 & $\begin{array}{c}\text { Больше половины образца опусти- } \\
\text { лась на дно, захватив достаточную } \\
\text { часть НП }\end{array}$ \\
\hline 4-0,4ШЦ & 0.095 & 0.081 & 4 & 3 & $\begin{array}{c}\text { Значительная часть образца опусти- } \\
\text { лась на дно вместе с частицами НП, } \\
\text { при этом вся поверхность слоя НП } \\
\text { просветлела, слой НП стал тоньше }\end{array}$ \\
\hline
\end{tabular}

\section{Заключение}

Показано, что усиление структурообразования в полимерных композитах ПАА-клиноптилолит происходит благодаря межмолекулярным водородным связям, которые образуют дополнительную сетку, компенсирующую рост неоднородности и дефектности в граничных слоях. Комплексообразование с участием активных функциональных групп - амидной со стороны полимерной матрицы и силанольной со стороны минерального наполнителя и молекул воды подтверждено методом инфракрасной спектроскопии. Клиноптилолитовые породы по отношению к ПАА проявляют структурную активность и влияют на морфологию модифицированной полимерной матрицы. Эффективность этого влияния зависит от концентрации компонентов и максимальна при содержании ПАА 4 г в $100 \mathrm{~cm}^{3}$ водного раствора и 0.2 мас. \% минерального наполнителя.

Выявлено, что наполнение ПАА клиноптилолитовыми породами способствует повышению термической устойчивости материала на $3-4^{\circ} \mathrm{C}$. Методом КроутсаРедферна рассчитано, что пленки, полученные из водных растворов исходного полиакриламида $\left(4\right.$ г/100 $\left.\mathrm{cm}^{3}\right)$ и наполненных 0.2 мас. \% клиноптилолитовыми породами Холинского и Шивыртуйского месторождений, в температурном интервале 100$500^{\circ} \mathrm{C}$ теряют вес с низкой эффективной энергией активации 14.55 и $16.43 ; 19.80$ кДж/моль и порядком реакции 1.0 и $1.4 ; 1.8$. Следовательно, формирование полимерного композиционного материала происходит в диффузионной области и зависит от интенсивности перемешивания. Повышение порядка термолиза и величин эффективной энергии активации подтверждают формирование органоминеральных комплексов и усиление структуры полимерных композитов.

Установлено, что введение 0.2 мас. \% клиноптилолитового наполнителя Ши-

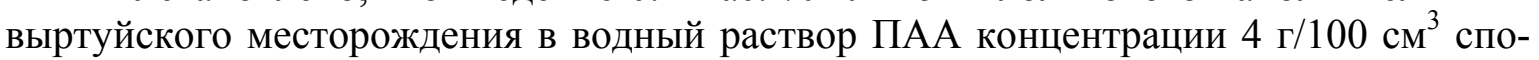


собствует значительному изменению структуры полимерной матрицы и сопровождается улучшением сорбционных свойств полимерного композиционного материала по отношению к нефти и дизельному топливу по сравнению с таковой для ненаполненного ПАА.

Исследования выполнены при финансовой поддержке Забайкальского института железнодорожного транспорта - филиала ФГБОУ ВО «Иркутский государственный университет путей сообщения» (грант НТС № 39-гр). Автор выражает благодарность м.н.с. ИПРЭК СО РАН Р.А. Филенко за регистращию кривых дифференщиально-сканирующей калориметрии и термогравиметрии, магистрантке ЗабГУ В.А. Трембач - за синтез образиов.

\section{Список литературы}

1. Huang P., Ye L. // J. of Thermoplastic Composite Materials. 2016. Vol. 29. Iss. 1. pp. 58-73.

2. Ferfera-Harrar H., Aiouaz N., Dairi N. // International Journal of Chemical, Molecular, Nuclear, Materials and Metallurgical Engineering. 2015. Vol. 9. No7. pp. 849-856.

3. Khai Ern Lee, Imran Khan, Norhashimah Morad, Tjoon Tow Teng, and Beng Teik Poh // Polymer Composites. 2011. Vol. 32. Iss. 10. pp. 1515-1522.

4. Bandura, L.; Franus M., Panek R.; Woszuk A.; Franus W. // Przem. Chem. 2015. Vol. 94. Iss. 3. pp. 323-327.

5. Muir B., Wołowiec M., Bajda T., Nowak P., Czupryński P. // Mineralogia. 2017. Vol. 48. No 1-4. pp. 145-156.

6. Сироткина Е.Е., Новоселова Л.Ю. // Химия в интересах устойчивого развития. 2005. T. 13. C. 359-377.

7. Дабижа О.Н., Дербенева Т.В., Хатькова А.Н., Филенко Р.А., Патеюк Т.П. // Химия в интересах устойчивого развития. 2016. Т. 24. № 2. C. 193-201.

8. Dechant J., Danz R., Kimmer W., Schmolke R. Infrarotspektroskopie untersuchungen an

\section{References}

1. Huang P., Ye L., J. of Thermoplastic Composite Materials, 2016, Vol. 29, Iss. 1, pp. 5873.

2. Ferfera-Harrar H., Aiouaz N., Dairi N., International Journal of Chemical, Molecular, Nuclear, Materials and Metallurgical Engineering, 2015, Vol. 9, No 7, pp. 849-856.

3. Khai Ern Lee, Imran Khan, Norhashimah Morad, Tjoon Tow Teng, and Beng Teik Poh, Polymer Composites, 2011, Vol. 32, Iss. 10, pp. 1515-1522.
Polymeren. Berlin. Akademie Verlag. 1972. 473 p.

9. Мошников В.А., Таиров Ю.М., Хамова Т.В., Шилова О.А. Золь-гель технология микро- и нанокомпозитов: учебное пособие / под ред. О.А. Шиловой. СПб. Лань. 2013. $304 \mathrm{c}$.

10. Каушанский Д.А., Демьяновский В.Б., Ступакова Т.П., патент РФ, № 2025466, 1994.

11. Сумм Б.Д., Горюнов Ю.В. Физикохимические основы смачивания и растекания. М. Химия. 1976. $231 \mathrm{c.}$

12. Кулагина Г.С. Автореф. дисс. канд. хим. наук. М. 2007. 22 с.

13. Лазарев А.Н. Колебательные спектры и строение силикатов. Л. Наука. 1968. 347 с.

14. Ситников П.А., Васенева И.Н., Белых А.Г. // Известия Коми научного иентра УРО PAH. 2011. № 4 (8). C. 15-18.

15. Липатов Ю.С. Физическая химия наполненных полимеров. М. Химия. 1977. $304 \mathrm{c.}$

16. Золотов С.М., Фирсов П.М., Клиценко К.А. // Збірник наукових праць УкрДУЗТ. 2016. Вип. 161. С. 157-169.

4. Bandura, L., Franus, M., Panek, R., Woszuk, A., Franus, W., Przem. Chem., 2015, Vol. 94, Iss. 3, pp. 323-327.

5. Muir B., Wołowiec M., Bajda T., Nowak P., Czupryński P., Mineralogia, 2017, Vol. 48, No 1-4, pp. 145-156.

6. Sirotkina E.E., Novoselova L.Yu., Chemistry for Sustainable Development, 2005, Vol. 13 , pp. 359-377.

7. Dabizha O.N., Derbeneva T.V., Khat'kova A.N., Filenko R.A., Pateyuk T.P., Chemistry for 
Sustainable Development, 2016, Vol. 24, No 2, pp. 193-201.

8. Dechant J., Danz R., Kimmer W., Schmolke

$\mathrm{R}$. Infrarotspektroskopie untersuchungen an Polymeren, Berlin, Akademie Verlag, 1972, 473 p. (Russ. ed.: Dekhant I. Infrakrasnaya spektroskopiya polimerov, Moscow, Chemistry Publ., 1976, 472 p).

9. Moshnikov V.A., Tairov Yu.M., Xamova T.V., Shilova O.A. Sol-gel technology of microand nanocomposites: uchebnoe posobie / pod red. O.A. Shilovoj. SPb., Lan', 2013, 304 p.

10. Kaushanskij D.A., Dem yanovskij V.B., Stupakova T.P., patent RF, no 2025466, 1994.

Дабижа Ольга Николаевна - к.х.н., доцент, доцент кафедры химии, Забайкальский государственный университет, Забайкальский край, Чита; старший научный сотрудник научноисследовательской лаборатории «Фундаментальные и прикладные физико-химические исследования материалов» научно-исследовательского проектно-технологического бюро «ЗабИЖТИнжиниринг», Забайкальский институт железнодорожного транспорта, Забайкальский край, Чита
11. Summ B.D., Goryunov Yu.V. Physicochemical basis of wetting and spreading, M., Chemistry, 1976, $231 \mathrm{p}$.

12. Kulagina G.S. Avtoref. diss. kand. him. nauk. Moscow, 2007, 22 p.

13. Lazarev A.N. Vibrational spectra and structure of silicates, L., Nauka, 1968, 347 p.

14. Sitnikov P.A., Vaseneva I.N., Bely`x A.G., Izvestiya Komi nauchnogo centra URO RAN, 2011, No 4 (8), pp. 15-18.

15. Lipatov Yu.S. Physical Chemistry of Filled Polymers, M., Chemistry, 1977, 304 p.

16. Zolotov S.M., Firsov P.M., Klicenko K.A., Zbirnik naukovix pracz' UkrDUZT, 2016, Vip. 161, pp. 157-169.

Dabizha Olga N. - Candidate of Chemistry, Associate Professor, Associate Professor of the Department of Chemistry, Transbaikal State University, Zabaikalsky Territory, Chita, Senior Researcher of the research laboratory "Fundamental and Applied Physical and Chemical Materials Research" of the Research and Design Bureau "Zabizht-Engineering", Zabaikalsky Institute of Railway Transport, Zabaikalsky Territory, Chita, e-mail: dabiga75@mail.ru 